\title{
Summary of: \\ Side effects of external tooth bleaching: a multi-centre practice- based prospective study
}

\author{
E. M. Bruzell, ${ }^{* 1}$ U. Pallesen ${ }_{1}^{2}$ N. Rygh Thoresen ${ }_{1}^{3}$ C. Wallman ${ }^{4}$ \\ and J. E. Dahl ${ }^{5}$
}

VERIFIABLE CPD PAPER

FULL PAPER DETAILS

'Senior Researcher, Nordic Institute of Dental Materials (NIOM), Sognsveien 70A, NO-0855 Oslo, Norway: ${ }^{2}$ Chief Dental Officer, Department of Cariology and Endodontics, School of Dentistry, University of Copenhagen, Nørre Allé 20, DK-2200 Copenhagen N, Denmark; ${ }^{3}$ Lecturer, Cariology and Gerodontology, Institute of Clinical Dentistry, Faculty of Dentistry, University of Oslo, P.O. Box 1109 Blindern NO-0317 Oslo, Norway; ${ }^{4}$ Associate Professor, Institut of Clinical Dentistry/Faculty of Medicine, University of Troms $\varnothing$, N0-9,037 Tromsø, Norway; ${ }^{5}$ Managing

Director, Nordic Institute of Dental Materials (NIOM), P.O. Box 3874 Ullevål stadion, NO-0805 Oslo, Norway and Professor, Institute of Clinical Dentistry, Faculty of Dentistry, University of Oslo, P.O. Box 1109 Blindern, NO-0317 Oslo, Norway

${ }^{*}$ Correspondence to: E. M. Bruzell

Email:ebr@niom.no; Tel: +47 67512200

Refereed Paper

Accepted 16 July 2013

DOI: $10.1038 /$ sj.bdj.2013.1047

-British Dental Journal 2013; 215: E17

Objective The study was performed to assess the risk of at-home and in-office bleaching procedures, and to recognise potential predictors for side effects. Design Multi-centre, questionnaire-based prospective study with follow-ups at around 14 days and around one year post-treatment. Setting General practices and university clinics during the years 2007-2009 in Scandinavia. Subjects Patients with tooth bleaching as part of the treatment plan. Results The prevalence of experienced tooth sensitivity at first follow-up was independent of bleaching procedure (at-home $=50.3 \%$ [ $n=143]$; in-office $=39.3 \%[n=28] ; p>0.05 ; 95 \% \mathrm{Cl}[\mathrm{OR}]: 0.198-1.102)$ whereas prevalence of gingival irritation was higher after in-office treatment (at-home $=14.0 \%$; in-office $=35.7 \%$; $p<0.05$ ) (mean age: 37.3 years; $73.7 \%$ women; $n=171$ ). At the second follow-up, two and three patients reported side effects attributed to the bleaching treatment in the at-home and in-office groups, respectively. Predictors for side effects were tooth sensitivity, surface loss and gingivitis when observed at inclusion. Treatment-related predictors were bleaching concentration and contact between tray and gingiva. Conclusions Bleaching treatment, irrespective of method, caused a high prevalence of side effects. Patients associated with the predictors at inclusion mentioned above should be notified of the risk for side effects and treated only if bleaching is indicated based on a proper diagnosis.

\section{EDITOR'S SUMMARY}

'Our primary concern is for your safety'. So begins the introduction to most announcements preceding the descriptions of emergency procedures on aircraft should some rare and awful circumstance occur. Interestingly the insistence of the pilot that however frequently passengers fly the information is still important and they should please take notice underlines how the majority of travellers take it all for granted. I would suggest that the reason is that they have already weighed the risks against the benefit. Their perception is that the chance of a serious incident is so rare that it doesn't warrant looking up from their Sudoku or crossword and in any case is off-set by the advantage of being able to get to their chosen destination quickly and comfortably.
The same might also be said for tooth bleaching and is, I believe, borne out by the results of this useful piece of research on the safety of the various differing procedures. The recent enormous growth in tooth whitening has caused a minor revolution in dental practice and, as importantly, a sea-change in patients' views of what is available to make them look, and feel, better.

Just as with the in-flight announcements the fact that patients are prepared to put up with (as distinct from 'suffer') any subsequent discomfort in the interests of what might cynically be called vanity, but probably more generously termed aesthetics, is testament to their personal decisions to balance risk with benefit.

Be that as it may, it does not remove or lessen our need as professionals to advise patients as to the possible side- effects or disadvantages of tooth whitening treatment. This research is therefore valuable as it enables us to do so as fully and comprehensively as possible based on a wide range of literature, practical experience and reported incidents. The fact that the procedures are for the most part free of problems, and in those cases where there are side-effects they are relatively minor in nature, is reassuring for all concerned. While we should not be complacent we should be pleased that such a widely used treatment is as safe as it appears to be.

The full paper can be accessed from the $B D J$ website (www.bdj.co.uk), under 'Research' in the table of contents for Volume 215 issue 9.

Stephen Hancocks Editor-in-Chief DOI: 10.1038/sj.bdj.2013.1070 


\section{TO ACCESS THE BDJ WEBSITE TO READ THE FULL PAPER:}

- BDA Members should go to www.bda.org.

- Click the 'login' button on the right-hand side and enter your BDA login details.

- Once you have logged in click the 'BDJ' tab to transfer to the BDJ website with full access.

IF YOUR LOGIN DETAILS DO NOT WORK:

- Get a password reminder: go to www.bda.org, click the login button on the right-hand side and then click the forgotten password link.

- Use a recommended browser: we recommend Microsoft Internet Explorer or Mozilla Firefox.

- Ensure that the security settings on your browser are set to recommended levels.

IF YOU HAVE NOT YET SIGNED UP TO USE THE BDA WEBSITE:

- Go to www.bda.org/getstarted for information on how to start using the BDA website.

\section{IN BRIEF}

- Provides numbers and types of side-effects reported after and during in-office and at-home bleaching treatments.

- Identifies factors that may increase the risk for onset of side effects.

- Describes reports of complaints of discomfort attributed to bleaching treatments up to a year later.

- Gives a realistic 'picture' of the numbers and types of side effects that can be expected in a similar population.

\section{COMMENTARY}

One of the biggest challenges in teeth whitening processes is sensitivity to the soft tissues and the teeth while carrying out treatments. The side effects can be so severe that some patients discontinue the treatments, as demonstrated in this paper. The sensitivity caused by in-office teeth whitening can be very severe when a very high concentration of hydrogen peroxide is used in conjunction with heat lamps during the procedure. This paper looked at the short- and long-term side effects of both home and in-office teeth whitening procedures across different treatment centres from universities to private clinics. The training and protocol of carrying out these treatments might vary from location to location, including bleaching tray design, bleaching products used and contact time with the active agents. It is well documented in the literature that both treatments caused soft tissue and pulpal sensitivity during and after treatments. Yet this is the first time a longer term study has evaluated any lingering side effects after one year of treatment in both procedures. The different types of side effects were clearly identified and discussed. This paper showed that side effects were usually short term, lasting a few days, with no long-term side effects associated with the teeth whitening treatments. It is interesting to find that those patients who had sensitivity with the treatments were more satisfied with their results.

The authors reviewed and quoted literature that supported the findings in this paper. This paper is of special interest to me as my $\mathrm{PhD}$ thesis was on the efficacy and safety of teeth whitening processes. I have also reviewed the literature mentioned in this paper and most of them report the symptoms from various teeth whitening processes, utilising different strengths of bleaching agents. In-office teeth whitening using very high concentrations of hydrogen peroxide is a very complex procedure and the soft tissues need to be protected properly from the caustic effect of the strong chemicals used. It would be helpful if more research was performed into finding out the real causes of these symptoms to eventually find solutions for these, to make teeth whitening a pain-free experience for the patients in the near future.

\section{Dr Wyman Chan}

Clinical Associate Teacher

Warwick Dentistry

University of Warwick

\section{AUTHOR QUESTIONS AND ANSWERS}

1. Why did you undertake this research? The group of authors saw a need for an investigation on side effects and efficacy of tooth bleaching in a study that included a larger number of patients and with a longer follow-up time than usually reported. Furthermore, we became aware of individual cases of long-term discomfort or pain that the patients related to previous tooth bleaching treatment, and we hoped to obtain more information on this aspect. We also wanted to gain more insight into which method, in-office or athome bleaching with trays, would cause the least side effects, as available reports were not conclusive.

2. What would you like to do next in this area to follow on from this work?

Data was also acquired on the efficacy of tooth bleaching, from the at-home and in-office groups. In-office treatment was performed as light-assisted bleaching and bleaching without light. This efficacy data will also be compiled and analysed. It would be of interest to investigate the frequency, degree and duration of side effects after repeated treatments. Relevant information could be obtained from investigations performed according with the EU-directive on the use of tooth bleaching products, ie dentist-supervised and with bleaching concentrations less than or equal to $6 \%$ hydrogen peroxide. As there seems to be uncertainty about the impact of bleaching on enamel and dentine it should be investigated whether the risk is increased with prolonged and/or repeated treatments in a clinical setting. 